\title{
Gone with the plate: the opening of the Western Mediterranean basin drove the diversification of ground-dweller spiders
}

\author{
Leticia Bidegaray-Batista* and Miquel A Arnedo
}

\begin{abstract}
Background: The major islands of the Western Mediterranean-Corsica, Sardinia, and the Balearic Islands-are continental terrenes that drifted towards their present day location following a retreat from their original position on the eastern Iberian Peninsula about 30 million years ago. Several studies have taken advantage of this welldated geological scenario to calibrate molecular rates in species for which distributions seemed to match this tectonic event. Nevertheless, the use of external calibration points has revealed that most of the present-day fauna on these islands post-dated the opening of the western Mediterranean basin. In this study, we use sequence information of the cox1, nad1, 16S, L1, and 12S mitochondrial genes and the 18S, 28S, and h3 nuclear genes, along with relaxed clock models and a combination of biogeographic and fossil external calibration points, to test alternative historical scenarios of the evolutionary history of the ground-dweller spider genus Parachtes (Dysderidae), which is endemic to the region.
\end{abstract}

Results: We analyse 49 specimens representing populations of most Parachtes species and close relatives. Our results reveal that both the sequence of species formation in Parachtes and the estimated divergence times match the geochronological sequence of separation of the main islands, suggesting that the diversification of the group was driven by Tertiary plate tectonics. In addition, the confirmation that Parachtes diversification matches welldated geological events provides a model framework to infer substitution rates of molecular markers. Divergence rates estimates ranged from $3.5 \% \mathrm{My}^{-1}$ (nad1) to $0.12 \% \mathrm{My}^{-1}$ (285), and the average divergence rate for the mitochondrial genes was $2.25 \% \mathrm{My}^{-1}$, very close to the "standard" arthropod mitochondrial rate $\left(2.3 \% \mathrm{My}^{-1}\right)$.

Conclusions: Our study provides the first unequivocal evidence of terrestrial endemic fauna of the major western Mediterranean islands, whose origin can be traced back to the Oligocene separation of these islands from the continent. Moreover, our study provides useful information on the divergence rate estimates of the most commonly used genes for phylogenetic inference in non-model arthropods.

\section{Background}

The estimation of the timing of evolutionary events from DNA sequence information has become a major research topic in evolutionary biology. Although the use of molecular data to estimate divergence times goes back to the mid 60 's of the past century [1], the number of studies that include time estimation has increased rapidly over the last decade due to the ever increasing amount of DNA sequence data and the development of new algorithms that relax the limiting assumptions of

\footnotetext{
* Correspondence: letigaray@yahoo.com

Institut de Recerca de la Biodiversitat \& Departament de Biologia Animal, Universitat de Barcelona, Av. Diagonal 643, 08020, Barcelona, Spain
}

the molecular clock (see reviews of [2-4]). Information on timescales has shed light not only on the origin of taxonomic groups but has also allowed for the testing of biogeographic and climatic hypotheses, the estimation of rates of species diversification, and the investigation of rates of molecular evolution, among other topics [5].

Genetic distances are transformed into absolute divergence times by incorporating calibration points. The choice of a specific calibration date is therefore potentially crucial to accurately infer molecular dates (e.g., [6]). Biogeographic and paleoecological data are among the main sources of information for dating phylogenetic nodes, either as a complement to the fossil record, or as
C Biomed Central

() 2011 Bidegaray-Batista and Arnedo; licensee BioMed Central Ltd. This is an Open Access article distributed under the terms of the Creative Commons Attribution License (http://creativecommons.org/licenses/by/2.0), which permits unrestricted use, distribution, and reproduction in any medium, provided the original work is properly cited. 
the only available evidence in poorly preserved organisms. The use of geologic and paleoclimatic evidence, however, has been criticised on the basis of their limited accuracy and unwarranted assumptions (e.g., [7-9]). Therefore, the appropriate use of biogeographic events to calibrate phylogenies requires a well-documented geochronology and the demonstration that the assumed barriers constitute a true obstacle to dispersal for the focal group.

The complex geological evolution of the western Mediterranean region, located at the edge of the converging African and Eurasian plates, is relatively well understood [10-17] and has been extensively used for molecular dating (e.g., [18-24]) as well as to explain present-day species distributions (e.g., [25]). The opening of the western Mediterranean basin started during the Alpine orogeny, when an eastward tectonic extension occurred between the African and Eurasian plates due to a subduction rollback between the oceanic and the continental slab (back arc extension). As a result, at the beginning of the Oligocene ( $30-25$ million years ago, Ma), several continental microplates that formed part of the Hercynian belt (Corsica, Sardinia, Balearic Islands, Calabro-Peloritan massif, including northern Sicily, the Kabylies and the Beatic-Rift Cordillera) broke off and started drifting from the eastern Iberian Peninsula and southern France to their present-day location (Figure 1(A)). During the first stage of the back arc extension, the northern microplate assemblage (Sardinia, Corsica and Calabro-Peloritan massif) started drifting counter-clockwise with respect to the Eurasian plate, whereas the southern assemblage (the Balearic Islands and Great Kabylie) drifted clockwise relative to Iberia. The movement of the northern microplates resulted in the opening of the Ligurian Sea, the Valencia Trough and the Gulf of Lyon. Corsica, Sardinia and the Calabro-Peloritan massif collided with the Apulian plate around 20-18 Ma, completing the formation of the Gulf of Lyon. There is no general consensus on the time of separation of Corsica and Sardinia, although it almost certainly occurred during the Corsica-Sardinia rotation. This rotation has been dated to approximately 21-15 Ma [13,26] based on paleomagnetic data and is further corroborated by the presence of early Burdigalian marine sediments in southern Corsica [27]. Likewise, there are doubts about the time when the exotic blocks of the Calabro-Peloritan massif drifted off from Sardinia to their present-day positions, although it is generally accepted that it occurred during the formation of the Tyrrhenian Sea $[10,17]$. According to Rosenbaum \& Lister [28], the Tyrrhenian Sea started opening 10-9 Ma in the northern and western part, finishing around 5-4 Ma in the southern part. The same geological processes that generated the Tyrrhenian Sea also broke off the land connection between the Maghrebides and Sicily, opening the Strait of Sicily [12]. The Provençal and the Algerian basins are both older than the Tyrrhenian Sea, and originated during the Early-Middle Miocene (21-15 Ma), when the Kabylies block broke off from the Balearic Islands $(\sim 21$ $\mathrm{Ma}$ ) and started drifting southward until they collided with the African margin (18-15 Ma). The formation of the Alboran basin is a matter of debate because the original position of the Rif-Betic mountain range is uncertain $[12,15]$. Some authors suggest that during the Oligocene, the Rif-Betic mountain range formed a continuous orogenic belt together with the western Alps, Calabria, Corsica and the Kabylies blocks [12]. At the time of the main subduction rollback, the Rif-Betic block drifted southwest up to its present location $(\sim 10$ $\mathrm{Ma})$, completing the formation of the Alboran basin.

Although the formation of the main western Mediterranean islands has been used to date evolutionary divergence times and to explain species ranges, most studies using independent calibration points or substitution rates estimated from related organisms have concluded that the origin of present-day fauna in the region greatly post-dates the opening of the basin [29-33]. In particular, the Messinian Salinity Crisis (MSC) has been pointed out as one of the main drivers of local diversification. The late Miocene ( $8 \mathrm{Ma}$ ) marine corridors in southern Iberia and northern Morocco closed about $5.96 \mathrm{Ma}$, isolating the Mediterranean Sea from the Atlantic Ocean and causing a large reduction in Mediterranean water levels and the emergence of land connections between North Africa, Corsica, Sardinia and Eurasia and between the Balearic Islands and Iberia $[34,35,16]$. The opening of the Strait of Gibraltar about 5.3 Ma restored the water exchange between the Atlantic and Mediterranean waters, reestablishing effective isolation of the island ecosystems [36,37]. To date, the plant family Araceae constitutes the only case reported of Mediterranean organisms in which diversification has been shown to correspond to the Oligocene break-off of the Hercynian belt [38].

The ground-dweller spider genus Parachtes Alicata, 1964 (Araneae, Dysderidae) is a promising candidate for a terrestrial animal whose diversification may have been shaped by western Mediterranean plate tectonics. This genus is restricted to the western Mediterranean, where it exhibits a disjunct distribution [39]. It currently includes 12 species: P. ignavus Simon, 1882 and P. inaequipes Simon 1882 from Corsica, P. limbarae Kraus, 1955 from Sardinia, P. siculus Caporiacco, 1949 from Sicily, P. romandiolae Caporiacco, 1949, P. vernae Caporiacco, 1936, P. latialis Alicata, 1966 and P. andreinii Alicata, 1966 from the Italian Peninsula, and P. cantabrarum Simon, 1914, P. teruelis Kraus, 1955, P. loboi Jiménez-Valverde, 2006 and P. deminutus Denis, 1957 


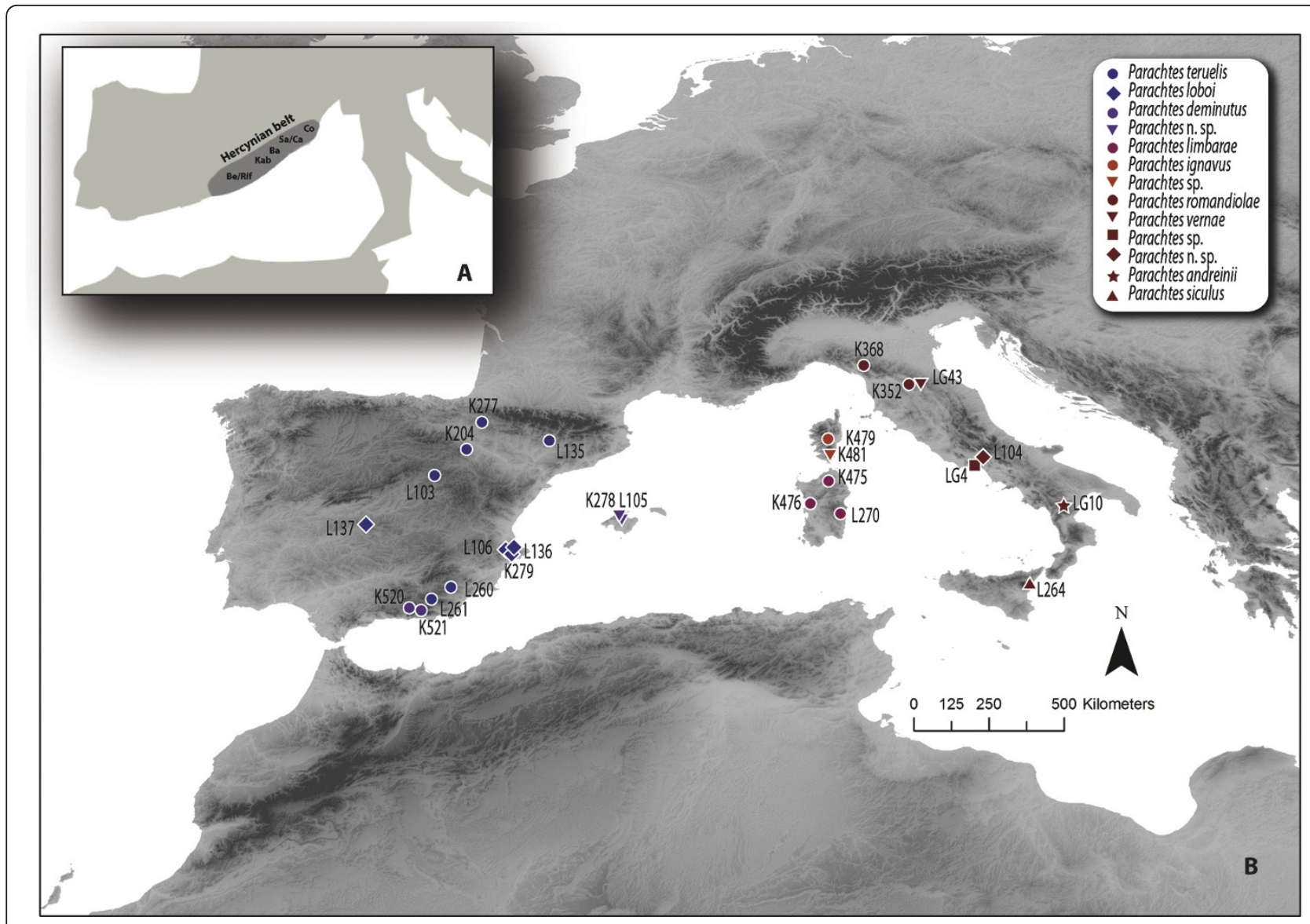

Figure 1 Maps of the western Mediterranean Basin. (A) Map showing the presumed location of the microplates that formed part of the Hercynian belt (modified from Rosenbaum et al.[12]). Microplate names are indicated as follow: Be/Rif corresponds to theBetic/Rift plate, Kab to the Kabylies, Ba to the Balearic Islands, Sa/Ca to Sardinia/Calabria and Co to Corsica. (B) Map showing sampling locations and codes of Parachtes specimens sampled. Species are indicated by symbols and colours (see legends in the upper right box); the colours correspond to the main lineages indicated in Figure 2 and Figure 3. See Additional file 1 for detailed information of sample codes.

from the Iberian Peninsula. Two new species, one endemic to Majorca (Balearic Islands) and another to the Italian Peninsula (Lazio), have been recently discovered and are awaiting formal description (Arnedo, unpublished data). Parachtes shows a remarkable uniformity in its somatic morphology and most species' diagnostic features are restricted to the male and female genitalia [39]. Parachtes species are nocturnal wandering hunters, usually found in leaf-litter, under dead logs or stones and in dark and humid habitats at mid to high altitudes (> $500 \mathrm{~m}$ ). These spiders do not build webs, and ballooning (i.e., aerial dispersal by means of silk threads) has been reported neither in the genus nor in the whole family. The low vagility and habitat preferences suggest limited opportunities for overseas dispersal, although transport by floating islands has been proposed to explain colonisation of the oceanic Canary Islands by the closely related genus Dysdera [40].
Here, we investigate the role of the major geological events associated with the opening of the Western Mediterranean basin in shaping diversification of the spider genus Parachtes, by inferring a molecular phylogeny based on eight mitochondrial and nuclear genes from a thorough taxonomic sampling of the genus and its close relatives. Relaxed clock models in combination with multiple, independent biogeographic and fossil calibration points are further used to reconstruct the temporal framework of species diversification.

\section{Results}

\section{Samples and sequences analysed}

The specimens and sequences analysed in the present study are summarised in Additional file 1. The alignment of the non-protein coding genes, including informative gap characters coded as absence/presence characters (see Additional file 2 for details), were 
merged with the protein-coding genes $(\operatorname{cox} 1=1257$, nad $1=358$ and $h 3=327$ characters), resulting in a combined matrix of 4454 characters for the "default alignment", 4462 for the "gappy alignment" and 4447 for the "compressed alignment". Gap characters were included in the parsimony and Bayesian inference analyses but excluded in maximum likelihood and divergence time analyses.

\section{Phylogenetic analyses}

Preliminary analysis using parsimony conducted on the concatenated matrices of the default, gappy and compressed alignments resulted in almost identical topologies and similar jackknife supports, although jackknife values were slightly higher for the default alignments (Figure 2). The $12 S$ and $16 S-L 1$ genes were the most variable and hence the most sensitive to changes in the alignment parameter values, recovering slightly different topologies. Differences, however, involved unsupported alternative positions.

Bayesian inference and maximum likelihood analyses were only conducted on the default alignment concatenated matrix, because no remarkable differences were found among the resulting topologies of each alignment. The selected substitution models for each gene and gene partition are shown in Additional file 3. Phylogenetic analyses under the three inference methods and partition strategies resulted in almost identical topologies, summarised in Figure 2.

All methods support the monophyly of Parachtes and its sister group relationship to the western Mediterranean species of Harpactocrates. As suspected [41], the eastern European species currently included in Harpactocrates did not form a clade with its western counterparts. The most basal split in the genus Parachtes separates species of the Iberian Peninsula (Iberian clade) from those of the western Mediterranean islands, Italy and the Betic species (Hercynian-Italian clade). Although all analyses support this basal split, the support for the Hercynian-Italian clade was moderate to low (parsimony jackknife 67\%, Bayesian posterior probability 0.95 , maximum likelihood bootstrap 51\%), and the AU topology test could not reject the alternative topology where all Iberian and the Balearic species formed a clade sister to the remaining species $(\mathrm{p}=$ $0.464,0.469,0.473$, for P1, P2 and P3, respectively). Maximum likelihood and Bayesian inference analyses conducted on P2 and P3 partition schemes, however, increased support for the Hercynian-Italian clade (72/ 0.96 and 84/0.98, respectively, see Figure 2). The Hercynian-Italian clade was further resolved into two clades, one clade including the Balearic and Betic species, and a second clade where the Italian species form a monophyletic group sister to Corsica, with both of them in turn sister to Sardinia. All of the former clades were highly supported.

\section{Temporal framework of Parachtes diversification}

Bayes factor analysis provided decisive support for selecting relaxed clock models against the strict clock, but could not discriminate between the two Bayesian relaxed clocks. The lognormal model, however, yielded the highest harmonic mean likelihood and was used in subsequent analyses. Likewise, BEAST analyses using Yule as tree prior yielded the highest likelihood harmonic means, but provided no strong evidence as compared to the more complex birth-death models. Finally, Bayes factors indicated decisive evidence in favour of the P3 partition scheme over the alternative schemes (Bayes factors summarised in Additional file 4).

The chronogram with corresponding confidence intervals obtained with the preferred analysis options is shown in Figure 3 . The time of the split between the Iberian clade and the Hercynian-Italian clade was estimated at 23.16 Ma (31.81-15.32 Ma), while the time of divergence between the Balearic-Betic clade and the Sardinian-Corsican-Italian clade was estimated at $19.17 \mathrm{Ma}$ (26.63-12.24). The Baleares and the Betic clades split at 9.73 Ma (16.14-4.09). Sardinia split from the CorsicanItalian clade at $14.34 \mathrm{Ma}$ (20.81-9.00), and the Corsican lineage split from the Italian clade at $11.27 \mathrm{Ma}$ (16.286.65), similar to the estimated time of divergence of the two Iberian species $P$. loboi and P. teruelis, $11.09 \mathrm{Ma}$ (17.39-5.50). The southern Italian species $P$. andreinii diverged from the remaining Italian species at $8.80 \mathrm{Ma}$ (12.93-4.96). Italian P. siculus and P. vernae split from P. romandiolae and P. n. sp. at $5.90 \mathrm{Ma}$ (9.14-3.23). The most recent species splits correspond to the two former pairs, at 3.20 Ma (5.40-1.26) and $1.69 \mathrm{Ma}$ (3.14-0.56), respectively.

The substitution rates inferred for each gene partition were (mean pairwise divergence $\left.\mathrm{My}^{-1}\right): 3.5 \%$ (nad1), $2.5 \%$ (cox 1$), 1.7 \%(12 S), 1.3 \%$ (16S-L1), $0.22 \%(h 3)$ and $0.12 \%(28 S)$ (Table 1). The $18 S$ substitution rate could not be estimated due to low genetic variability and limited phylogenetic resolution. All genes evolved in a nonclocklike manner, as indicated by ucld.stdev values and the high coefficient of variation, which reflects heterogeneity in substitution rates along tree branches. The nuclear gene $28 \mathrm{~S}$ showed higher deviation from the strict clock, as ucld.stev and the coefficient of variation were greater than 1. Moreover, the 95\% HPD interval of the covariance values span zero in all genes, which means that there is not evidence of autocorrelation of rates in the phylogeny (see BEAST user manual).

The lineage age estimates obtained in r8s under the preferred method selected by cross-validation analyses for the different partition schemes are summarised in 


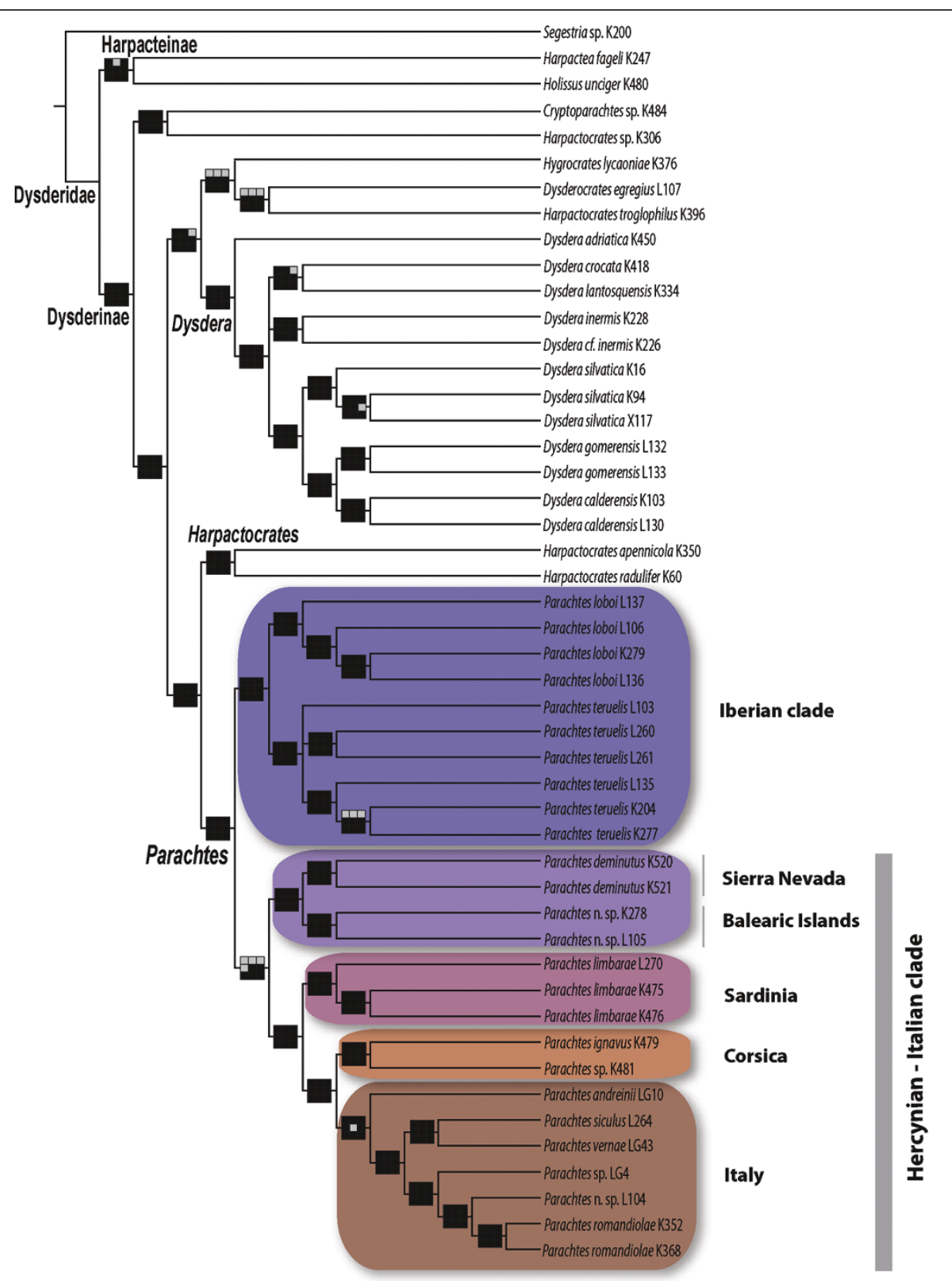

Figure 2 Strict consensus of the six most parsimonious trees. The most parsimonious tree (8458 steps, Cl: 33 , Rl: 62) obtained from the default alignment, summarising parsimony, maximum likelihood and Bayesian inference supports. Clade support: black square, supported by Parsimony jackknife $>70 \%$, Maximum likelihood bootstrap $>70 \%$, and Bayesian posterior probability $>0.95$; grey square, clade recovered but with support below the threshold value above; white squares, clade not recovered. Upper line: parsimony on default alignment (left), parsimony on gappy alignment (centre), parsimony on compressed alignment (right); middle line: Maximum likelihood on partition scheme P1 (left), P2 (centre), P3 (right); lower line: Bayesian inference on partition scheme P1 (left), P2 (centre), P3 (right).

Additional file 5. Differences among divergence time estimation methods and partition strategies at different phylogenetic levels were assessed by monitoring the following clades: the Dysderidae node, the Parachtes node, and the Corsican-Italian node. The analyses performed with r8s and BEAST yielded similar estimates for the Parachtes and the Corsica-Italian nodes, but differed greatly for the deeper Dysderidae node (see Figure 4).

\section{Discussion}

Timing of Parachtes diversification

Although our discussion and conclusions are based on the time estimates obtained using Bayesian methods, we 


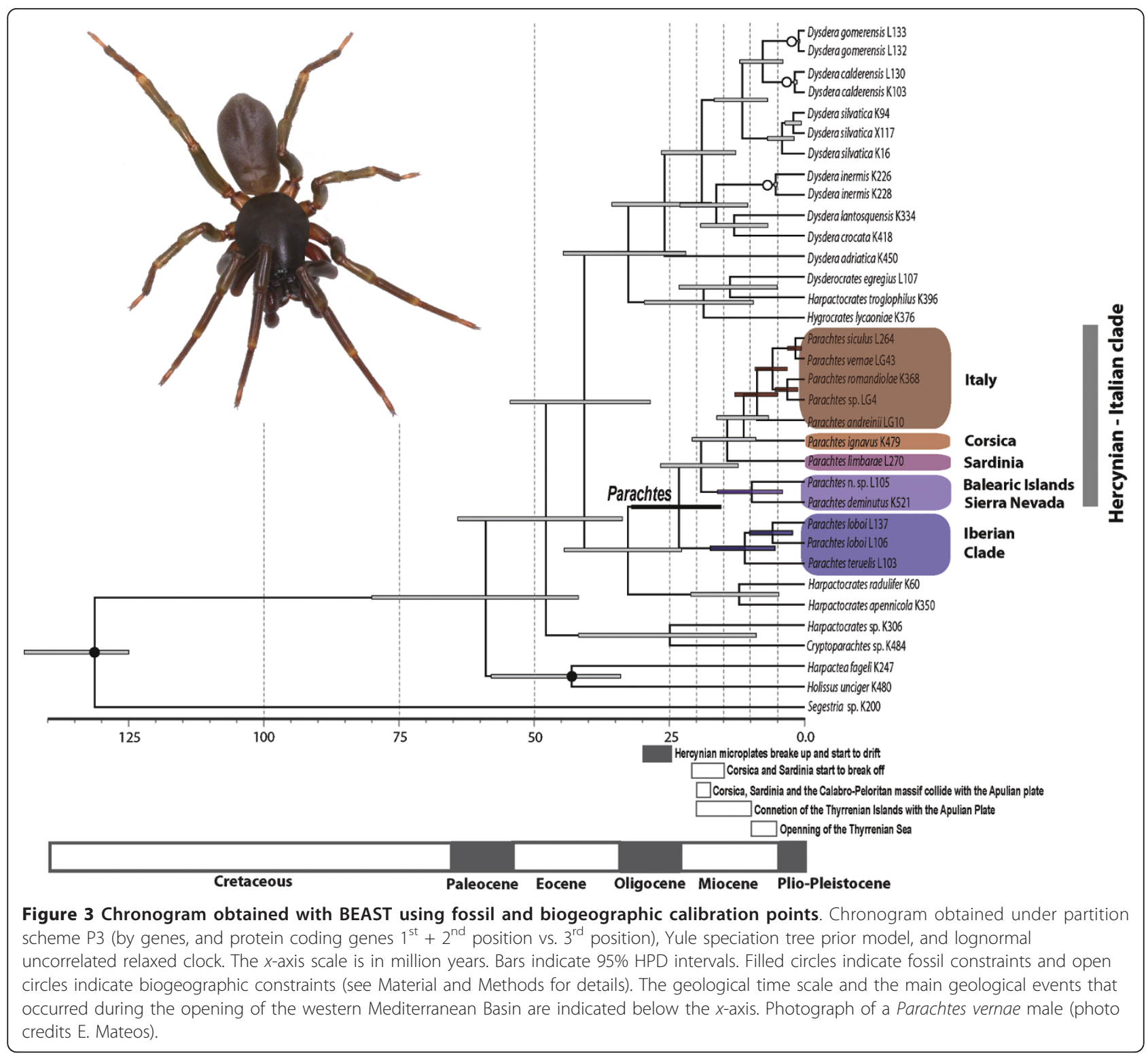

Table 1 Estimated substitution rates per gene obtained with BEAST based on fossil and biogeographic calibration points

\begin{tabular}{cccccc}
\hline Gene & Mean Rate & ucld.mean & ucld.stdev & Coefficient Variance & Covariance \\
\hline cox1 & 0.0125 & 0.0199 & 0.6668 & 0.7087 & 0.0254 \\
& $(0.0089-0.0165)$ & $(0.0136-0.0270)$ & $(0.4780-0.8728)$ & $(0.4823-0.9635)$ & $(-0.2254-0.2960)$ \\
nad1 & 0.0177 & 0.0258 & 0.6390 & 0.6400 & 0.0003 \\
& $(0.0115-0.0240)$ & $(0.0163-0.0362)$ & $(0.4395-0.8792)$ & $(0.4088-0.8978)$ & $(-0.2474-0.2699)$ \\
12S & 0.0087 & 0.0128 & 0.6950 & 0.7272 & -0.0115 \\
& $(0.0057-0.0119)$ & $(0.0080-0.0181)$ & $(0.4080-1.0218)$ & $(0.3649-1.1102)$ & $(-0.2637-0.2773)$ \\
16-L1 & 0.0063 & 0.0091 & 0.5731 & 0.5576 & -0.0183 \\
& $(0.0046-0.0082)$ & $(0.0063-0.0124)$ & $(0.4032-0.7500)$ & $(0.3818-0.7309)$ & $(-0.02596-0.2543)$ \\
h3 & 0.00108 & 0.0013 & 0.6450 & 0.6332 & -0.0125 \\
& $(0.0006-0.0016)$ & $(0.0007-0.0019)$ & $(0.3241-1.0006)$ & $(0.2918-0.9781)$ & $(-0.2216-0.2089)$ \\
28S & 0.0006 & 0.0011 & 1.2490 & 1.4518 & 0.1892 \\
& $(0.0003-0.0008)$ & $(0.0005-0.0019)$ & $(0.8895-1.6582)$ & $(0.9805-1.9531)$ & $(-0.0572-0.4451)$ \\
\hline
\end{tabular}

Estimations obtained under uncorrelated lognormal relaxed clock. Lower and upper bounds of the 95\% HPD are indicated between brackets. Mean Rate: number of substitutions per site across the tree divided by the tree length. Ucld.mean: mean of the branches rates. 


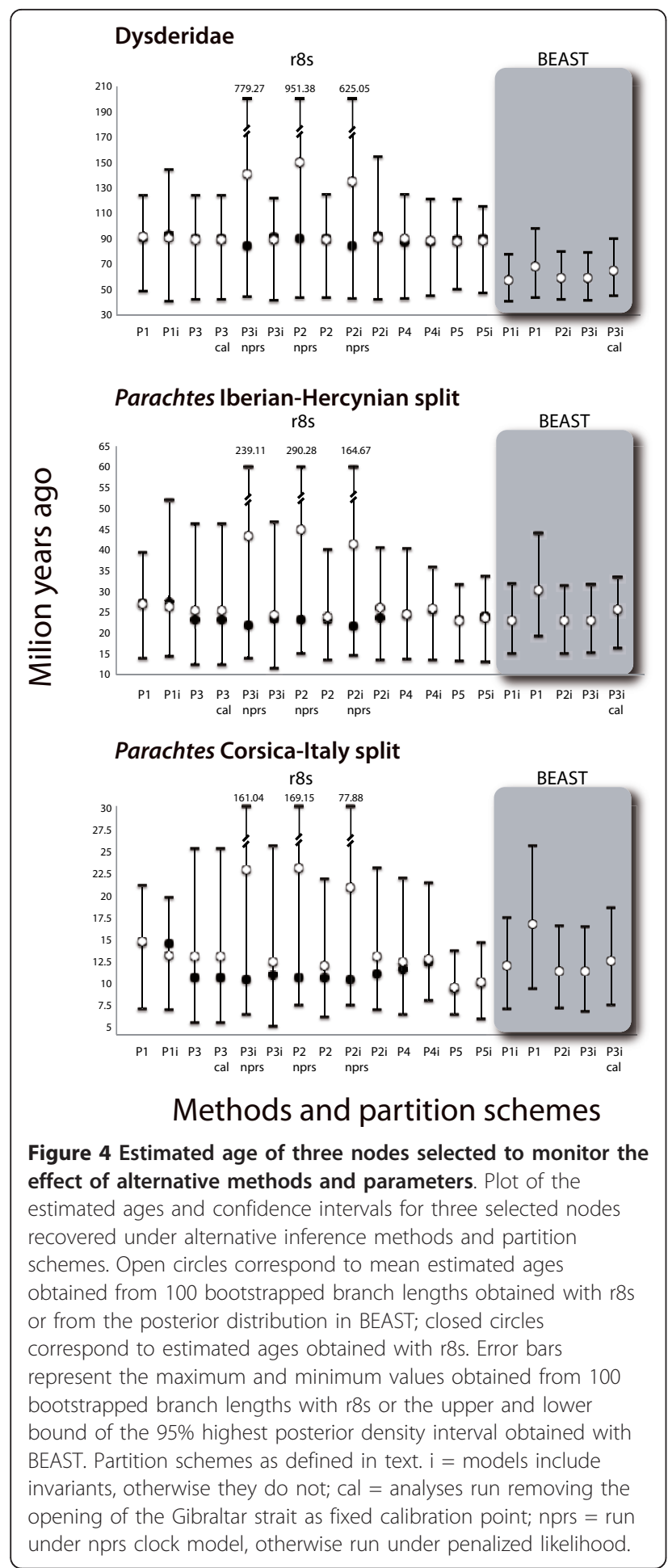

also investigated estimates based on alternative, widelyused smoothing methods. The results showed that time estimates of Parachtes diversification are consistent across methods and data partition schemes. The two time estimation methods, however, greatly differed at older time splits, suggesting that there could be incorrect assumptions under certain analytical conditions. Smoothing methods differ from Bayesian methods, as implemented in BEAST, by the use of fixed topologies and roots and by assuming rate autocorrelation between ancestral and descendant branches [2-4,42]. To date, there has been a limited advance in evaluating the strengths and weaknesses of both methods, because direct comparisons between them are hampered by their numerous differences [3]. Finding out the causes of the reported discrepancies are beyond the scope of this study, but our results recommend exerting caution when trying to estimate ages close to the root.

The tree topology and estimated divergences identify the opening of the Western Mediterranean basin as the main driver for the diversification of Parachtes species (Figure 2, 3 and 5). The estimated age for the split of the Parachtes stem group closely matches the geochronology of the Hercynian belt break-off, and these node age estimates are robust to alternative analytical procedures and to partition schemes (Figure 4). Therefore, our results reject previous suggestions for a Quaternary origin of the genus [39], mostly based on the absence of these species from the Rift and Kabylies regions in northern Africa. Indeed, the absence of Parachtes in northern African exotic terrains poses a challenge to the Miocene origin hypothesis. It may be argued that biotic surveys of the region are far from complete, and that, hence, the presence of the species cannot be completely ruling out. Alternative explanations, such as species extinction due to unfavourable climatic conditions seem unlikely given that other humid fauna with northern Mediterranean affinities, such as the Salamandra newts [43] or Alytes toads [44], are still found in northern Africa. Evidence of absence is always hard to prove, and further exhaustive, systematic biotic surveys of northwestern Africa will be necessary to discard the presence of Parachtes in the region.

Most current evidence indicates that Corsica, Sardinia, northern Sicily, the Balearic Islands, and the Kabylies microplates were part of a single block by the time of the onset of the back arc extension ( 30-25 Ma), when the microplates broke and drifted off the Iberian Peninsula $[10,12,14,15,28,17]$. Nevertheless, the actual location of the Rift-Betic block is still controversial. It has been suggested that the internal part of the Rift-Betic belt was laid near the Balearic Hercynian microplates (see Figure seven of [15]). Some authors go further and propose that the Balearic microplate, together with the Betic belt, formed a Betic-Balearic domain, which suffered a WNW progressive thrust sheet stacking during the back arc extension, ending approximately at the time of the Middle-Miocene (16.4-11.2 Ma) [45,46]. The existence of a Betic-Balearic corridor during the Langhian-Serravallian marine regression (Middle Miocene, 
(1)

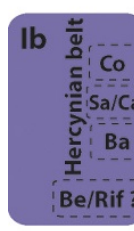

(2)

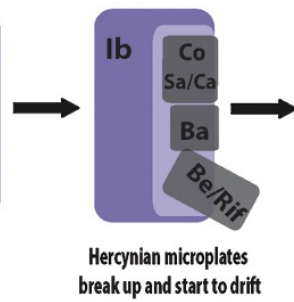

(30-25 Ma)
(3)

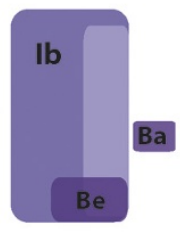

Corsica and Sardinia + the Calabro-Peloritan massif start to break off (21-15 Ma), and collide with the Apulian plate (20-18 Ma)
(4)

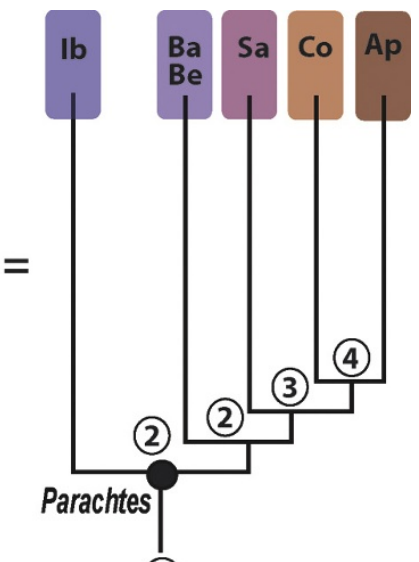

(1)

Figure 5 Reconstruction of the paleobiogeographic scenario for Parachtes diversification. Scenario 1, 2, 3 and 4 represent main geological events that occurred during the opening of the western Mediterranean Basin. Contemporary areas of species distribution are indicated as follows: Ib, Iberian microplate; Co, Corsica; Sa, Sardinia; Ca, Calabria; Ba, Balearic Islands; Be/Rif, Betic/Rift microplate and Ap, Apulian microplate. Current species distribution is indicated at the tips of the inferred topology, and the colours correspond to areas previously defined. The putative geological event involved in the diversification process is indicated at each node.

c. 14.2 Ma) has been proposed to explain the origin of some Balearic mammalian fossil remains [47]. Alternatively, the Betic-Balearic clade could be the result of a later colonisation facilitated by the land bridge connections between the Balearic Islands and the continent established during the Messinian Salinity Crisis [21,48]. However, our much older time estimates disagree with this scenario.

The sister group relationship of the Sardinian lineage with the remaining Thyrrenian and the Italian species together with the divergence time of these two lineages (14.34 Ma, 20.81-9 Ma) are consistent with the time frame of the separation of Corsica from Sardinia, dated at 21-15 Ma [12]. A similar phylogenetic pattern, i.e., Sardinia as a sister group of Corsica and Italy, has also been reported in the subterranean aquatic stenasellid isopods [20] and the terrestrial isopod Helleria brevicornis [32], although in the latter case time estimates suggest an Early Pleistocene split of Corsica and Sardinia.

The close relationships between Corsican and northern Italian species revealed in Parachtes have also been recovered in a diverse assemblage of arthropods, including cave crickets, wasps or isopods [20,49-51,32]. In most cases, these links originated as a result of active dispersal during the Pleistocene glacial cycles (2-0.5 $\mathrm{Ma}$ ), when recurrent marine regressions led to the formation of land bridges between Corsica and Tuscany or when the Tuscany archipelago could have been used as stepping-stones. Our results, however, point towards a deeper split between the Corsican and Italian lineages (11.27, 16.26-6.68 Ma), which matches the onset of the opening of the Tyrrhenian Sea. About 10-9 Ma, Corsica, Sardinia and the Calabro-Peloritan massif separated from the Apennines, after having progressively collided with the Apulian plate at around 20-18 Ma [12,28].

The basal split of Italian P. andreinii was estimated at about $9 \mathrm{Ma}$. Similar divergence times were found between northern and southern Italian species of the Salamandrina spectacled salamanders [52]. However, the finding of Miocene-age Salamandrina fossils in Sardinia led some authors to propose a double origin for the Italian Salamandrina: the ancestor of the northern species would have colonised the Peninsula from Corsica/Sardinia, while the southern one would have drifted eastward from Sardinia on the Calabro-Peloritan massif. The double-origin hypothesis put forward for Salamandrina does not match the topology inferred for Parachtes. Italian Parachtes are monophyletic, and thus a double colonisation scenario would require extinction events on both the islands and the continent. Indeed, the lack of direct links between the Sardinian and any Italian lineage seems to be at odds with geological expectations, given that Sardinia was connected to the Apennines until the opening of the Tyrrhenian Sea [28] and given the biogeographic links such as those reported in cave salamanders of the genus Hydromantes [53] and Discoglossus toads [21].

With the exception of $P$. andreinii, the estimated timeframe suggests that the diversification of Parachtes in the Italian peninsula was mostly driven by Plio-Pleistocene glacial cycles, as already predicted by Alicata [39]. The key role of geographic isolation due to Quaternary climatic oscillations seems to explain the origin of other components of the Italian fauna, such as frogs and snakes [54-58]. Further comprehensive phylogeographical studies on Italian and Iberian Parachtes species 
are, however, needed to gain detailed insight into their evolutionary history and to fully expose the factors responsible for their diversification.

Recent studies have suggested that divergence time estimates under recently developed multilocus coalescent methods may provide younger time estimates than the standard concatenated approach conducted in the present study (see [59]). Although, this issue is still little explored in the literature, the amount of disagreement seems to be particularly significant at shallow divergence times. In fact, it has been argued that the younger estimates obtained with coalescent approaches may be the results of unaccounted recent gene flow [59], since most multilocus coalescent methods of species trees inference assume incomplete lineage sorting as the single source of gene tree incongruence (e.g., [60-62]).

\section{Estimates of substitution rates}

In the absence of fossil or biogeographic calibration points, the extrapolation of substitution rates from independent analyses provides the only information for inferring absolute timeframes. The confirmation that tectonic evolution of the Western Mediterranean shaped Parachtes diversification opens the possibility of using this model system to characterise substitution rates in molecular markers of interest.

The use of extrapolated substitution rates for one lineage and markers to date another may be compromised by the variation in rate of molecular evolution among lineages [63]. In the present study, the estimated average substitution rate for the mitochondrial genes estimated $\left(2.25 \% \mathrm{My}^{-1}\right)$ closely matches the "standard" arthropod mitochondrial DNA clock estimated at 2.3\% $\mathrm{My}^{-1}$ [64], one of the most widely used universal rates. These results are surprising, given that the analytical procedures and assumptions used to estimate rates widely differ in the two studies. Nevertheless, Papadopoulou et al. [65] have reached similar conclusions by using another well-dated geological event, the formation of the MidAegean Trench on the eastern Mediterranean, dated at 9-12 Ma, (from 2.39 to $2.69 \% \mathrm{My}^{-1}, 3.54 \%$ and $1.06 \%$, for mtDNA, cox 1 and 165 , respectively). These results may be viewed as a further support for the geological scenario proposed for Parachtes diversification.

The few spider rates available in the literature are significantly higher than the ones obtained here. Bond and collaborators [66] estimated a substitution rate for $16 \mathrm{~S}$ of $4 \% \mathrm{My}^{-1}$ in the trapdoor spider Aptostichus simus, while phylogeographic studies in woodlouse hunter spiders endemic to the Canary Island have reported cox 1 rates as high as $9.8 \% \mathrm{My}^{-1}$ [67] or $10.2 \% \mathrm{My}^{-1}$ [68]. Interestingly, the former rates were derived from population-level comparisons, which have been shown to produce higher estimates of mutation rates as compared to substitution rates inferred in phylogenetic (specieslevel) studies (Ho et al. [69]; however, see Emerson [7]). The slower estimates found in $\operatorname{cox} 1\left(1.75 \% \mathrm{My}^{-1}\right)$ in a species-level phylogeny of eastern Canarian Dysdera [70] supports this last contention.

Our study provides valuable information on the substitution rates of the handful of markers commonly used to infer phylogenies in non-model arthropods. Nextgeneration sequencing approaches promise to expand the range of molecular markers amenable to phylogenetic inference for organisms such as spiders. Until then, however, rigorous and thorough sampling of phylogeny of non-model organisms may rely on the set of genes used in the present study. In this context, our estimates could be an alternative to obtain absolute time estimates in the absence of calibration points when using such standard sets of molecular markers. Additionally, Parachtes may serve as a model system to gain further insights into the rate of molecular, morphological, and ecological trait evolution through time.

\section{Conclusions}

The pattern and timing of species formation in the spider genus Parachtes match the geochronological sequence of the opening of the western Mediterranean Basin. Therefore, Parachtes spiders provide one of the first and unequivocal pieces of evidence for endemic terrestrial taxa whose origins can be traced back to the separation of the major western Mediterranean islands from the continent (Figure 5). Our results confirm that early Oligocene tectonics played a key role in generating the diversity of the Earth's most populated biodiversity hot-spot $[34,71]$.

\section{Methods}

\section{Taxonomic sampling}

A total of 49 specimens were analysed in the present study (Additional file 1). We included 9 of the 12 currently known Parachtes species, along with two new species awaiting formal description: one from Majorca and one from the Italian Peninsula (Figure 1 (B)). The missing species included the Iberian P. cantabrorum, the Corsican $P$. inaequipes and the Italian P. latialis. $P$. cantabrorum from an undetermined locality in the Pyrenees [72] has not been collected since its original description (some females assigned to $P$. cantabrorum by Denis are most likely a misidentification, [73]). $P$. inaequipes is known from a single locality in southern Corsica (Bonifacio). One of the specimens included in the present analysis is an unidentified juvenile collected near the $P$. inaequipes type locality (Porto Vecchio, 23 $\mathrm{km})$. Finally, $P$. latialis is known from the Italian district of Lazio. After visiting this area, all collected specimens turned out to constitute a new species. 
Half of the Parachtes species were represented by single individuals, two by specimens sampled from 2 populations, 2 from 3 populations and one, P. teruelis, from 6 populations (Figure $1(\mathrm{~B})$ ). We sampled 14 additional species from 5 genera of the same subfamily (Dysderinae) and two genera of the subfamily Harpacteinae, which is also in the family Dysderidae. The genus Segestria, a member of the family Segestriidae closely related to Dysderidae and part of the same superfamily Dysderoidea, was included as an outgroup to root trees. The length of the most basal branch in a rooted tree with molecular clock not enforced is trivial and therefore has to be removed before estimating the divergence times using smoothing methods (see below). The most recent common ancestor of Dysderoids, however, provided a calibration point and, therefore, a specimen belonging to Caponiidae, the putative sister-family to Dysderoidea [74], was included to root analyses and preserve the Dysderoid node.

Most specimens were collected in the field by the authors; some were kindly provided by colleagues. Specimens were preserved in $95 \%$ ethanol and stored at $-20^{\circ} \mathrm{C}$ in the Department of Animal Biology of the University of Barcelona. Some specimens had been preserved in suboptimal 70\% ethanol, but extraction yielded reasonable amounts of DNA for specimens collected within the past 10 years.

\section{DNA extraction, PCR amplification and sequencing}

Genomic DNA was extracted from specimens using the DNeasy Tissue Kit (Qiagen) following the manufacturer's guidelines. Partial fragments of the mitochondrial genes cytochrome c oxidase subunit I ( $\operatorname{cox} 1)$, the $12 \mathrm{~S}$ rRNA (12S), a fragment spanning the 3' half of the $16 \mathrm{~S}$ rRNA ribosomal subunit (16S), the complete tRNA leu (L1) and the 5' half of the NADH deshydrogenase subunit I (nad1), and the nuclear genes 28S rRNA (28S), 18S rRNA (18S) and Histone H3 (h3), were amplified using the following primer pairs: [cox1] C1-J-1490 [75] and C1-N-2776 [76], alternatively as two overlapping fragments using primer pairs C1-J-1490 or C1-J-1718 [77] with C1-N-2198 [75] or C1-N-2191 [77] and CI-J-2183 [77] with C1-N-2776; [16S, L1, nad1] LR-N-13398 [77] and N1-J-12350 (Crates: 5'-CCTARTTGRCTARARTTRGCRSATCARCCAATTG-3') or N1-J-12373 [70], or as two overlapping fragments using primers pairs LR-N-13398 with LR-J-12864 [40] and LR-N12945 [78] with either N1-J-12350 or N1-J-12373; [12S] 12SR-J-14199 and 12SR-N-14594 [79] or 12SR-J-14215 (Viera: 5'-AGGGTGACGGGCGATATG TGCAC-3') and 12SR-N-14522 (Forlan: 5'-AAATTATATACTTTGGCGGC-3'); [28S] 28S-B [80] and 28S-O [76], or as two overlapping fragments using primers pairs 28S-A with 28S-B [80] and 28S-O with 28S-C [76];
[18S] 5F and 9R [80]; [h3] H3a F and H3a R [81]. PCR conditions were as follows: $2 \mathrm{~min}$. at $94^{\circ} \mathrm{C}$ followed by 35 cycles of denaturation at $94^{\circ} \mathrm{C}$ for $30 \mathrm{~s}$, annealing at $42-52^{\circ} \mathrm{C}$ for $35-45 \mathrm{~s}$ (depending on the primers, see below), and extension at $72^{\circ} \mathrm{C}$ for $30-60 \mathrm{~s}$ (depending on the length of the fragment), with a final single extension step at $72^{\circ} \mathrm{C}$ for $5 \mathrm{~min}$. For the cox1, 16S-nad 1 and $12 \mathrm{~S}$ gene fragments, a successful amplification was achieved with an annealing temperature of $42^{\circ} \mathrm{C}$ or $45^{\circ} \mathrm{C}$ for $45 \mathrm{~s}$. For the $18 S$ and $28 S$, a single annealing temperature of $52^{\circ} \mathrm{C}$ for $35 \mathrm{~s}$ was optimum. Finally, $h 3$ was amplified using a "touchdown" strategy consistent in beginning the annealing at $60^{\circ} \mathrm{C}$ for $35 \mathrm{~s}$ and lowering proportionally the temperature $1^{\circ} \mathrm{C}$ in each cycle (during 19 cycles), until reaching a constant temperature of $42^{\circ} \mathrm{C}$, keeping this annealing temperature during the following 16 cycles. Amplifications were carried out in a $25 \mu \mathrm{l}$ reaction volume for a final concentration of $1.25 \mathrm{U}$ Taq polymerase (Promega), $2.5 \mathrm{mM} \mathrm{MgCl}_{2}$ (Promega), 0.2 $\mathrm{mM}$ of each dNTP, $0.2 \mu \mathrm{M}$ of each primer and about 2 $\mu \mathrm{l}$ of DNA sample and the amount of Taq buffer recommended by the manufacturer. PCR products were purified using MultiScreen PCR $\mu 96$ cleanup filter plates from Millipore. PCR products were cycle-sequenced in both directions using one of the PCR primers and the BigDye Terminator v3.1 Cycle Sequencing Kit (Applied Biosystem) and sequenced in an ABI 3700 automated sequencer at the Scientific and Technical Services of the University of Barcelona [82]. DNA sequences were edited using Geneious v.5.0.3 [83].

\section{Phylogenetic Analyses}

The alignment of the $\operatorname{cox} 1$, nad 1 and $h 3$ gene sequences was trivial because there was no evidence for insertion/ deletion events and sequences were adjusted manually. Conversely, 12S, 16S-L1, $18 S$ and $28 S$ sequences showed length polymorphism, and gaps had to be included to retain positional homology. Sequence alignments of each variable length gene were constructed using the online version of the automatic alignment program MAFFT v. $6[84,85]$. The alignment was constructed using the manual strategy option set to Q-INS-i, with default options (Gap opening penalty $(\mathrm{GOP})=1.53$ and Offset value, which works like a gap extension penalty $($ GEP $)=0.0)$. Two additional alignments were constructed to explore the sensitivity of the phylogenetic results to alternative alignment parameter values. The parameter options were set as follows: $\mathrm{GOP}=3$ and GEP $=0$, to obtain a "compressed alignment", and GOP $=1$ and GEP $=0.5$, to obtain a "gappy alignment". Gaps were recoded as separate presence/absence characters following Simmons \& Ochoterena [86]. Treating gaps in this manner allows the incorporation of gap information in the analyses while minimising the effect of increasing 
the weight of overlapping multiple non-homologous gaps that result from scoring gaps as an additional state [87]. In addition, absence/presence gap scoring is amenable to Bayesian inference analyses. The program GapCoder [88] was used to facilitate the automatic recoding of the alignments based on the simple method proposed by Simmons et al. [89]. Gene matrices were concatenated using WINCLADA v.1.00.08 [90]. Non-sequenced fragments were scored as missing data.

Concatenation of genes evolving at different rates to resolve phylogenetic relationships among taxa across a wide range of divergence times has been the paradigm in phylogenetic inference for the last two decades. The use of concatenation is based upon the assumption that individual gene trees are congruent among themselves and to the species tree. However, it is well known that different genes may support incongruent topologies due to processes such as horizontal gene transfer, hybridization, gene duplication or incomplete lineage sorting [91-94]. This last problem is especially pervasive when dealing with closely related species, and has recently received a great deal of theoretical and methodological attention. A whole new generation of multispecies coalescent inference methods have been developed to deal with the effects of the stochasticity of the genealogical process. In the present study, however, we have decided to use a concatenation approach based on two main considerations: (1) we did not observe any instance of topological incongruence among individual gene trees, which lead us to assume that none processes know to cause gene incongruence had a major impact on our data, and (2) that our time window of interest (Oligocene/Miocene divergences) minimized the effect of coalescent stochastic errors (i.e. incomplete lineage sorting) in the sampled markers. Moreover, from a practical standpoint, the use of multiple coalescent approaches to infer species trees in the present study would have resulted in losing power to infer topology and branch lengths, given the taxonomic sampling (some species were represented by single individuals), and the low variability of the nuclear markers employed (slow evolving $18 S, 28 S$ and $h 3$ exon).

Parsimony analyses of the individual genes and concatenated matrices were conducted with the program TNT v. 1.0 [95]. Each heuristic search consisted of 1000 iterations of Wagner trees constructed with the random addition of taxa and subsequent TBR branch swapping, holding five trees per iteration and culminating in a final round of branch swapping holding up to 10000 trees. When the number of replicates finding optimal trees was less than $10 \%$, the number of replicates was increased by 1000 . Clade support was assessed via jackknife resampling [96] using 1000 replicates with individual heuristic searches consisting of 20 iterations of
Wagner tree construction using the random addition of taxa, holding 5 trees per iteration up to 10000 trees.

Bayesian inference analyses were conducted with MRBAYES v.3.1.2 [97] and were run remotely at the Bioportal computer resources of the University of Oslo [98]. The combined matrix was analysed under three scheme partitions: by gene (P1), by gene and mitochondrial protein coding genes $1^{\text {st }}+2^{\text {nd }}$ positions vs. $3^{\text {rd }}$ positions (P2), and by gene and protein coding genes (both mitochondrial and nuclear) $1^{\text {st }}+2^{\text {nd }}$ positions vs. $3^{\text {rd }}$ positions (P3). Nucleotide substitution models selected by the Akaike information criterion (AIC) [99], as implemented in jMODELTEST v.0.1.1 [100,101], were specified for each partition, and a standard discrete model was defined for the gaps scored as absence/presence data [102]. The substitution parameters were allowed to vary independently between each partition. Two independent runs of 10 million generations, sampling each 1000 generations, with six simultaneous MCMC (Markov Chain Monte Carlo) chains, each starting from random trees, were carried out simultaneously. The program TRACER v. 1.5 [103] was used to ensure that the Markov chains had reached stationarity by examining the effective sample size (ESS) values and also to determine the correct number of generations to discard as a burn-in for the analysis (first 10\%). Chain convergence was monitored by ensuring the standard deviation of the split frequencies of these two runs dropped below 0.01 .

Maximum likelihood analyses of the concatenated data matrix were conducted with the software program RAxML v. 7.0.4 [104] and run remotely at the CIPRES portal [105]. The same three partition schemes described above were analysed with independent GTR $+\mathrm{G}$ substitution models for each partition. The best likelihood tree was selected out of 100 iterations of the random addition of taxa. Non-parametric bootstrap support values were drawn from 100 resampled matrices. Finally, confidence values were mapped onto the best topology.

Trees were visualised and manipulated with the program FigTree v. 1.1.2 [106].

The Approximately Unbiased (AU) topology test [107] implemented in the computer program CONSEL v.0.1i [108] was used to investigate whether alternative topologies could be statistically distinguished (see Results).

\section{Estimation of divergence times and substitution rates}

The use of multiple calibration points results in better and more reliable estimations, while minimising associated uncertainty $[109,110]$. Absolute ages were thus estimated by incorporating both fossil and biogeographic calibration points, which provided minimum and fixed or maximum ages, respectively. The oldest fossil of the family Segestriidae has been found in Lebanese amber 
from the Lower Cretaceous [111]. Therefore, the minimum time of separation for the families Segestriidae and Dysderidae was set at 125 Mya. The Harpacteinae fossil genus Dasumiana Wunderlich, 2004 from Eocene Baltic amber [111] shows close morphological affinities in the male bulb with the present day genus Holissus (Arnedo, pers. obs.). This information was incorporated into the analysis by placing the minimum age estimate of the common ancestor of Harpactea and Holissus at 35 Mya. The closely-related genus Dysdera provided several biogeographic constraints. The split of the Iberian and Moroccan populations of Dysdera inermis was assumed to have been caused by the opening of the Strait of Gibraltar and therefore their time of divergence was set at 5.3 Mya. The time of a volcanic island formation provides a maximum age for the lineages inhabiting the island [112]. Dysdera has undergone local diversification in the volcanic archipelago of the Canary Islands, and inter-island populations of two endemic Canarian Dysdera species were used as additional biogeographic calibration points. The age of emergence of La Palma (2 Mya) and El Hierro (1.2 Mya) [113] placed maximum age estimates for the divergence time between the populations of La Palma and La Gomera of the species $D$. calderensis and for the divergence of the populations of El Hierro and La Gomera of the species D. gomerensis.

Minimum and maximum constraints were included as uniform prior distributions to estimate absolute time in a Bayesian framework (see below). Uniform prior distributions for fossil calibration were preferred over more explicit distributions (e.g., lognormal) as a conservative approach, given the limited information available to decide upon the shape of the distribution [114]. For island calibration points, upper bounds were set to the island age and lower bounds to zero. For fossils, the lower bound was set to the latest fossil age and the upper bound was set to 392 Mya, which is the age of the oldest Uraraneida, the putative sister taxon to spiders [115]. The opening of the Gibraltar strait was set as a fixed calibration point following a normal distribution, with mean $=5.3$ and $\mathrm{sd}=0.15$. The effect of using a fixed constraint on time estimates was explored by running additional analyses without this constraint.

Lineage ages were estimated using a Bayesian framework as implemented in BEAST v1.5.4 $[116,103]$ and using multiple rate methods as implemented in $\mathrm{r} 8 \mathrm{~s} \mathrm{v}$. 1.71 [117]. Species were represented by single specimens (Additional file 1) to avoid very short or zero-length branches, which may negatively influence the performance of the algorithms in r8s [117], and to ensure that only speciation processes as tree prior were included in BEAST estimations.

A preliminary cross-validation analysis was conducted to select the best clock method and, if required, the best smoothing parameter value [118] in r8s analyses. Analyses were conducted using the node constraints described above. Branch lengths were re-estimated with RAxML after taxon removal, enforcing the preferred topology under the alternative partitions schemes described above (P1, P2 and P3) and two additional schemes: gene partition with $3^{\text {rd }}$ codon positions removed (P4) and gene partitions with mitochondrial $3^{\text {rd }}$ codon positions removed (P5). Some concerns have been cast on the simultaneous use of invariants and gamma distributions in evolutionary models [119]. Therefore, branch lengths were reestimated under models with and without invariants for each partition model. Confidence intervals for the time estimates were constructed by generating 100 trees with identical topology by bootstrapping branch lengths, using RAxML.

We used an iterative strategy to select the best clock, partition and speciation model for conducting analyses in BEAST. Alternative schemes were compared using Bayes Factors, as calculated by the program TRACER v1.5. First, lineage ages were estimated under the strict and the two relaxed uncorrelated clocks (exponential and lognormal) using the partition scheme P1 (see above) and selecting the Yule speciation process as tree prior. Once the best clock model was identified, lineage ages were reestimated using the best clock and partition scheme P1, but selecting the Birth-death speciation process as a tree prior. Finally, lineage ages were estimated again by selecting the best clock and speciation process prior, under the three alternative partition schemes (P1, P2, and P3, see above). The best substitution model for each partition was assessed by AIC as implemented in jMODELTEST. An additional run was conducted without considering invariants in the nucleotide substitution models $\left(\mathrm{P} 1_{\mathrm{NOINV}}\right)$ under the partition scheme $\mathrm{P} 1$. Substitution rates were estimated for each gene under the uncorrelated lognormal relaxed clock, the Yule speciation process and the fixed topology in BEAST.

The ultrametric trees estimated with r8s were used as starting trees in BEAST analyses to ensure that time constraints were not violated. Two independent runs of 100 million generations, sampling every 10000 generations, were performed for each analysis. The convergence and mixing of each MCMC chain was assessed with TRACER. Both independent runs of each analysis were combined with LogCombiner after a $10 \%$ burn-in, and TreeAnnotator was used to summarise the information from the sampled trees.

\section{Additional material}

Additional file 1: Specimens and gene sequence information

Specimens and sequence accession numbers included in the study with details of sample codes, voucher number, sex (f: female, m: male, juv.: 
juvenile), and collection locality. Species names with asterisks were included in lineage age estimation analyses. † sequences obtained from different specimens to complete gene sampling nr: near.

Additional file 2: Length of the non-protein coding genes under different alignments. Default, compressed and gappy alignment lengths are indicated for each gene, along with numbers of gaps and informative gaps codified as absence/presence.

Additional file 3: Substitution models per gene and partitions selected by AIC. Nucleotide substitution models selected by AIC for a 48 taxon matrix used for phylogenetic analyses, and a 34 taxon matrix under different partitions used for lineage age estimations (see Material and Methods for details).

Additional file 4: Bayes factor comparisons for the selection of the clock model, the speciation process and the partition scheme. a) Bayes factor comparisons for selection between Yule and Birth-death speciation models under partition scheme P1. b) Bayes factor comparisons for selection among partition schemes P1, P2, P3 and P1 $1_{\text {NoInV }}$ (see Material and Methods for details). HME: Harmonic mean of the likelihood from the posterior distribution value.

Additional file 5: Estimated age of three nodes selected to monitor the effect of alternative methods and parameters. Ages of three selected nodes under different evolutionary models and partition schemes as estimated by R8S, using the best method selected by crossvalidation, and BEAST. In R8S analyses, branch lengths were first estimated with RAxML under a fixed topology in Figure 2 and GTR+ $\Gamma$ models, with (INV) or without invariants (NOINV). In BEAST, the best model was selected by jMODELTEST and, for P1 also without invariants ( $P 1_{\text {NoInv }}$ ). Partition schemes: by gene (P1, 4412 chars), by gene and mitochondrial protein coding genes $1^{\text {st }}+2^{\text {nd }}$ positions vs. $3^{\text {rd }}$ positions $(\mathrm{P} 2,4412$ chars), by gene and protein coding genes (both mitochondrial and nuclear) $1^{\text {st }}+2^{\text {nd }}$ positions vs. $3^{\text {rd }}$ positions ( $P 3,4412$ chars), by gene with $3^{\text {rd }}$ codon positions removed (P4, 3762 chars) and by gene with mitochondrial $3^{\text {rd }}$ codon positions removed (P5, 3871 chars). NPRS (Non Parametric Rate Smoothing), PL (Penalized Likelihood), log (logarithmic penalty function). S: Smoothing factor in PL. Age: estimated age. Confidence interval obtained by profiling across 100 trees of constrained topology and bootstrapped branch lengths, as estimated with RAXML: max (maximum value observed), min (minimum value observed), mean (average). 95\%HPD: upper and lower bound of the 95\% highest posterior density interval. †Analyses run removing the opening of the Gibraltar strait as fixed calibration point. *Preliminary cross validation analyses selected PL log as best fit but failed check. ${ }^{* *}$ Analyses under PL in partitions and models where cross-validation selected NPRS as best method, but obtained confidence intervals where absurdly large.

\section{Acknowledgements}

We thank H. López, N. Macías-Hernández, C. Hernando, E. de Mas, M. MejíaChang and V. Opatova, who assisted in the fieldwork. We would like to thank to S. Carranza, M.A. Ferrández, F. Gasparo, G. Giribet, K. Kunt, A. López, J. Pons, M. Rezac, C. Ribera, S. Taiti and N. Txasco for providing us with additional samples. We are grateful to J. Pons for assistance and support in some of the data analyses. We also thank W. Cavazza and G. Rosenbaum for their valuable comments that greatly improved the first versions of the manuscript. W. Wheeler made available sequence data collected by the ATOL Spider project (NSF grant EAR-0228699) for Caponia sp. This project was funded by the Spanish Ministry of Science and Innovation (MICINN) grant CGL2006-08617 (MA), and additional financial support was provided by project 2009SGR1462 from the Generalitat de Catalunya. LBB was supported by a graduate grant (FI-DGR 2009) from the Generalitat de Catalunya. MA was further supported by an ICREA Academia award for excellence in research from the Generalitat de Catalunya.

\section{Authors' contributions}

MA conceived the idea of the study, and MA and LBB designed the study. Specimens were collected by MA and LBB or kindly provided by colleagues. LBB did the molecular work. LBB and MA conducted the analyses. LBB wrote the first draft, and MA and LBB improved successive versions. Both authors read and approved the final manuscript.

Received: 15 July 2011 Accepted: 31 October 2011

Published: 31 October 2011

\section{References}

1. Zuckerkandl E, Pauling L: Evolutionary divergence and convergence in proteins. In Evolving genes and proteins. Edited by: Bryoson V, Vogel HJ. New York: Academic Press; 1965:97-166.

2. Renner SS: Relaxed molecular clocks for dating historical plant dispersal events. Trends Plant Sci 2005, 10:550-558.

3. Welch JJ, Bromham L: Molecular dating when rates vary. Trends Ecol Evol 2005, 20:320-327.

4. Rutschmann F: Molecular dating of phylogenetic trees: A brief review of current methods that estimate divergence times. Divers Distrib 2006, 12:35-48.

5. Weir JT, Schluter D: Calibrating the avian molecular clock. Mol Ecol 2008, 17:2321-2328.

6. Bromham L, Phillips MJ, Penny D: Growing up with dinosaurs: molecular dates and the mammalian radiation. Trends Ecol Evol 1999, 14:113-117.

7. Emerson BC: Alarm bells for the molecular clock? No support for Ho et al.'s model of time-dependent molecular rate estimates. Syst Biol 2007, 56:337-345.

8. Forest F: Calibrating the Tree of Life: fossils, molecules and evolutionary timescales. Ann Bot 2009, 104:789.

9. Heads M: Old taxa on young islands: a critique of the use of island age to date island-endemic clades and calibrate phylogenies. Syst Biol 2011, 60:204-218.

10. Gueguen E, Doglioni C, Fernandez M: On the post-25 Ma geodynamic evolution of the western Mediterranean. Tectonophysics 1998, 298:259-269.

11. Roca E, Sans M, Cabrera L, Marzo M: Oligocene to Middle Miocene evolution of the central Catalan margin (northwestern Mediterranean). Tectonophysics 1999, 315:209-229.

12. Rosenbaum G, Lister GS, Duboz C: Reconstruction of the tectonic evolution of the western Mediterranean since the Oligocene. J Virtual Explorer 2002, 8:107-126.

13. Speranza F, Villa IM, Sagnotti L, Florindo F, Cosentino D, Cipollari P, Mattei M: Age of the Corsica-Sardinia rotation and Liguro-Provençal Basin spreading: new paleomagnetic and Ar/Ar evidence. Tectonophysics 2002, 347:231-251.

14. Carminati E, Doglioni C: Mediterranean tectonics. In Encyclopedia of Geology. Edited by: Selley RC, Cocks LRM, Plimer IR. Amsterdam, The Netherlands: Elsevier; 2004:135-146.

15. Rosenbaum G, Lister GS: Formation of arcuate orogenic belts in the western Mediterranean region. In Orogenic Curvature: Integrating Paleomagnetic and Structural Analyses. Edited by: Sussman AJ, Weil AB. Boulder, Colorado: Geological Society of America Special Paper 383; 2004:41-56.

16. Jolivet L, Augier R, Robin C, SuC JP, Rouchy JM: Lithospheric-scale geodynamic context of the Messinian salinity crisis. Sediment Geol 2006, 188:9-33.

17. Schettino A, Turco E: Plate kinematics of the Western Mediterranean region during the Oligocene and Early Miocene. Geophys J Int 2006, 166:1398-1423.

18. Caccone A, Milinkovitch MC, Sbordoni V, Powell JR: Molecular biogeography: using the Corsica-Sardinia microplate disjunction to calibrate mitochondrial rDNA evolutionary rates in mountain newts (Euproctus). J Evol Biol 1994, 7:227-245.

19. Caccone A, Sbordoni V: Molecular biogeography of cave life: a study using mitochondrial DNA from Bathysciine beetles. Evolution 2001, 55:122-130.

20. Ketmaier V, Argano R, Caccone A: Phylogeography and molecular rates of subterranean aquatic Stenasellid Isopods with a peri-Tyrrhenian distribution. Mol Ecol 2003, 12:547-555.

21. Fromhage $L$, Vences $M$, Veith $M$ : Testing alternative vicariance scenarios in Western Mediterranean discoglossid frogs. Mol Phylogen Evol 2004, 31:308-322.

22. Fochetti R, Sezzi E, de Figueroa JMT, Modica MV, Oliverio M: Molecular systematics and biogeography of the western Mediterranean stonefly 
genus Tyrrhenoleuctra (Insecta, Plecoptera). J Zool Syst Evol Res 2009, 47:328-336.

23. Pfenninger M, Véla E, Jesse R, Elejalde MA, Liberto F, Magnin F, MartínezOrtí A: Temporal speciation pattern in the western Mediterranean genus Tudorella P. Fischer, 1885 (Gastropoda, Pomatiidae) supports the Tyrrhenian vicariance hypothesis. Mol Phylogen Evol 2010, 54:427-436.

24. Ribera I, Fresneda J, Bucur R, Izquierdo A, Vogler AP, Salgado JM, Cieslak A: Ancient origin of a Western Mediterranean radiation of subterranean beetles. BMC Evol Biol 2010, 10:29.

25. Magri D, Fineschi S, Bellarosa R, Buonamici A, Sebastiani F, Schirone B, Simeone MC, Vendramin GG: The distribution of Quercus suber chloroplast haplotypes matches the palaeogeographical history of the western Mediterranean. Mol Ecol 2007, 16:5259-5266.

26. Gattacceca J, Deino A, Rizzo R, Jones DS, Henry B, Beaudoin B, Vadeboin F: Miocene rotation of Sardinia: New paleomagnetic and geochronological constraints and geodynamic implications. Earth Planet Sci Lett 2007, 258:359-377.

27. Alvarez W: Fragmentation of the Alpine orogenic belt by microplate dispersal. Nature 1974, 248:309-314.

28. Rosenbaum G, Lister GS: Neogene and Quaternary rollback evolution of the Tyrrhenian Sea, the Apennines, and the Sicilian Maghrebides. Tectonics 2004, 23:1-17.

29. Carranza S, Amat F: Taxonomy, biogeography and evolution of Euproctus (Amphibia: Salamandridae), with the resurrection of the genus Calotriton and the description of a new endemic species from the Iberian Peninsula. Zool J Linn Soc 2005, 145:555-582.

30. Ketmaier V, Giusti F, Caccone A: Molecular phylogeny and historical biogeography of the land snail genus Solatopupa (Pulmonata) in the peri-Tyrrhenian area. Mol Phylogen Evol 2006, 39:439-451.

31. Zangari F, Cimmaruta R, Nascetti G: Genetic relationships of the western Mediterranean painted frogs based on allozymes and mitochondrial markers: evolutionary and taxonomic inferences (Amphibia, Anura, Discoglossidae). Biol J Linn Soc 2006, 87:515-536.

32. Gentile G, Campanaro A, Carosi M, Sbordoni V, Argano R: Phylogeography of Helleria brevicornis Ebner 1868 (Crustacea, Oniscidea): Old and recent differentiations of an ancient lineage. Mol Phylogen Evol 2010, 54:640-646.

33. Salvo G, Ho SYW, Rosenbaum G, Ree R, Conti E: Tracing the temporal and spatial origins of island endemics in the Mediterranean region: a case study from the citrus family (Ruta L., Rutaceae). Syst Biol 2010, 59:705-722.

34. Blondel J, Aronson J: Biology and wildlife of the Mediterranean region Oxford, New York: Oxford University Press; 1999.

35. Krijgsman W, Hilgen FJ, Raffi I, Sierro FJ, Wilson DS: Chronology, causes and progression of the Messinian salinity crisis. Nature 1999, 400:652-655.

36. Loget N, Driessche JVD, Davy P: How did the Messinian Salinity Crisis end? Terra Nova 2005, 17:414-419.

37. Loget N, Van Den Driessche J: On the origin of the Strait of Gibraltar. Sediment Geol 2006, 188:341-356.

38. Mansion G, Rosenbaum G, Schoenenberger N, Bacchetta G, Rossello JA, Conti E: Phylogenetic analysis informed by geological history supports multiple, sequential invasions of the Mediterranean Basin by the angiosperm family Araceae. Syst Biol 2008, 57:269-285.

39. Alicata P: Le specie italiane di Harpactocrates e di Parachtes n. gen. (Araneae, Dysderidae). Annuar ist Mus Zool Univ Napoli 1964, 16:1-40.

40. Arnedo MA, Oromí P, Ribera C: Radiation of the spider genus Dysdera (Araneae, Dysderidae) in the Canary Islands: Cladistic assessment based on multiple data sets. Cladistics 2001, 17:313-353.

41. Deeleman-Reinhold CL, Deeleman PR: Revision des Dysderinae. Tijdschr Entomol 1988, 131:141-269.

42. San Mauro D, Agorreta A: Molecular systematics: a synthesis of the common methods and the state of knowledge. Cell Mol Biol Lett 2010, 15:311-341.

43. Escoriza D, Comas MM, Donaire D, Carranza S: Rediscovery of Salamandra algira Bedriaga, 1833 from the Beni Snassen massif (Morocco) and phylogenetic relationships of North African Salamandra. Amphib-Reptilia 2006, 27:448-455.

44. Martínez-Solano I, Gonçalves HA, Arntzen JW, García-París M: Phylogenetic relationships and biogeography of midwife toads (Discoglossidae Alytes). J Biogeogr 2004, 31:603-618.

45. Fontboté JM, Guimerà J, Roca E, Sàbat F, Santanach P, FernándezOrtigosa F: The Cenozoic geodynamic evolution of the Valencia trough (western Mediterranean). Rev Soc Geol España 1990, 3:249-259.
46. Roca E: La evolución geodinámica de la Cuenca Catalano-Balear y áreas adyacentes desde el Mesozoico hasta la actualidad. Acta Geol Hisp 1994, 29:3-25.

47. Bailon S, Bover P, Quintana J, Alcover JA: First fossil record of Vipera Laurenti 1768. Comptes Rendus Palevol 2010, 9:147-154.

48. Bover P, Quintana J, Alcover JA: Three islands, three worlds: paleogeography and evolution of the vertebrate fauna from the Balearic Islands. Quatern Int 2008, 182:135-144.

49. Allegrucci G, Todisco V, Sbordoni V: Molecular phylogeography of Dolichopoda cave crickets (Orthoptera, Rhaphidophoridae): A scenario suggested by mitochondrial DNA. Mol Phylogen Evol 2005, 37:153-164.

50. Dapporto L, Wolf H, Strumia F: Recent geography determines the distribution of some flying Hymenoptera in the Tuscan Archipelago. J Zool 2007, 272:37-44

51. Martinsen L, Venanzetti F, Bachmann L: Phylogeography and mitochondrial DNA divergence in Dolichopoda cave crickets (Orthoptera, Rhahidophoridae). Hereditas 2009, 146:33-45.

52. Nascetti G, Zangari F, Canestrelli D: The spectacled salamanders, Salamandrina terdigitata (Lacépède, 1788) and S. perspicillata (Savi, 1821): 1) genetic differentiation and evolutionary history. Rend Fis AcC Lincei 2005, 16:159-169.

53. Carranza S, Romano A, Arnold EN, Sotgiu G: Biogeography and evolution of European cave salamanders, Hydromantes (Urodela: Plethodontidae), inferred from mtDNA sequences. J Biogeogr 2007, 35:724-738.

54. Canestrelli D, Cimmaruta R, Nascetti G: Phylogeography and historical demography of the Italian treefrog, Hyla intermedia, reveals multiple refugia, population expansions and secondary contacts within peninsular Italy. Mol Ecol 2007, 16:4808-4821.

55. Canestrelli D, Verardi A, Nascetti G: Genetic differentiation and history of populations of the Italian treefrog Hyla intermedia: lack of concordance between mitochondrial and nuclear markers. Genetica 2007, 130:241-255.

56. Canestrelli D, Cimmaruta R, Nascetti G: Population genetic structure and diversity of the Apennine endemic stream frog, Rana italica-insights on the Pleistocene evolutionary history of the Italian peninsular biota. $\mathrm{Mol}$ Ecol 2008, 17:3856-3872.

57. Canestrelli D, Nascetti G: Phylogeography of the pool frog Rana (Pelophylax) lessonae in the Italian peninsula and Sicily: multiple refugia, glacial expansions and nuclear-mitochondrial discordance. J Biogeogr 2008, 1923-1936.

58. Barbanera F, Zuffi MAL, Guerrini M, Gentilli A, Tofanelli S, Fasola M, Dini F: Molecular phylogeography of the asp viper Vipera aspis (Linnaeus, 1758) in Italy: evidence for introgressive hybridization and mitochondrial DNA capture. Mol Phylogen Evol 2009, 52:103-114.

59. McCormack JE, Heled J, Delaney KS, Peterson AT, Knowles LL: Calibrating divergence times on species trees versus gene trees: implications for speciation history of Aphelocoma jays. Evolution 2010, 65:184-202.

60. Liu L: BEST: Bayesian estimation of species trees under the coalescent model. Bioinformatics 2008, 24:2542-2543.

61. Kubatko LS, Carstens BC, Knowles LL: STEM: species tree estimation using maximum likelihood for gene trees under coalescence. Bioinformatics 2009, 25:971-973.

62. Heled J, Drummond AJ: Bayesian inference of species trees from multilocus data. Mol Biol Evol 2010, 27:570-580.

63. Bromham L, Penny D, Rambaut A, Hendy MD: The power of relative rates tests depends on the data. J Mol Evol 2000, 50:296-301.

64. Brower AVZ: Rapid morphological radiation and convergence among races of the butterfly Heliconius erato inferred from patterns of mitochondrial DNA evolution. Proc Natl Acad Sci USA 1994, 91:6491-6495.

65. Papadopoulou A, Anastasiou I, Vogler AP: Revisiting the insect mitochondrial molecular clock: the mid-Aegean trench calibration. Mol Biol Evol 2010, 27:1659-1672.

66. Bond JE, Hedin MC, Ramirez MG, Opell BD: Deep molecular divergence in the absence of morphological and ecological change in the Californian coastal dune endemic trapdoor spider Aptostichus simus. Mol Ecol 2001, 10:899-910.

67. Macías-Hernández N, Oromí P, Arnedo MA: Integrative taxonomy uncovers hidden species diversity in woodlouse hunter spiders (Araneae, Dysderidae) endemic to the Macaronesian archipelagos. Syst Biodivers 2010, 8:531-553.

68. Bidegaray-Batista L, Macías-Hernández N, Oromí P, Arnedo MA: Living on the edge: demographic and phylogeographical patterns in the 
woodlouse-hunter spider Dysdera lancerotensis Simon, 1907 on the eastern volcanic ridge of the Canary Islands. Mol Ecol 2007, 16:3198-3214.

69. Ho SYW, Phillips MJ, Cooper A, Drummond AJ: Time dependency of molecular rate estimates and systematic overestimation of recent divergence times. Mol Biol Evol 2005, 22:1561-1568.

70. Macías-Hernández N, Oromí P, Arnedo MA: Patterns of diversification on old volcanic islands as revealed by the woodlouse hunter spider genus Dysdera (Araneae, Dysderidae) in the eastern Canary Islands. Biol J Linn Soc 2008, 94:589-615.

71. Myers N, Mittermeier RA, Mittermeier CC, da Fonseca GA, Kent J: Biodiversity hotspots for conservation priorities. Nature 2000, 403:853-858

72. Simon E: Synopsis général et catalogue des espèces fraçaises de l'ordre des Araneae: 1re partie. Les Arachnides de France Paris 1914, 6:1-308.

73. Ferrández MA: Notes on the Iberian Dysderidae, IV. New records, cartography and biology of $R$. scutiventris Simon, 1882 (Araneae). Bol Asoc Esp Entomol 1990, 14:33-40.

74. Ramírez MJ: Respiratory system morphology and the phylogeny of haplogyne spiders (Araneae, Araneomorphae). J Arachnol 2000, 28:149-157.

75. Folmer O, Black M, Hoeh W, Lutz R, Vrijenhoek R: DNA primers for amplification of mitochondrial cytochrome $\mathrm{c}$ oxidase subunit I from diverse metazoan invertebrates. Mol Mar Biol Biotechnol 1994, 3:294-299.

76. Hedin MC, Maddison WP: A combined molecular approach to phylogeny of the jumping spider subfamily Dendryphantinae (Araneae: Salticidae). Mol Phylogen Evol 2001, 18:386-403.

77. Simon C, Frati F, Beckenbach A, Crespi B, Liu H, Flook P: Evolution, weighting, and phylogenetic utility of mitochondrial gene sequences and a compilation of conserved polymerase chain reaction primers. Ann Entomol Soc Am 1994, 87:651-701.

78. Hedin MC: Speciational history in a diverse clade of habitat-specialized spiders (Araneae: Nesticidae: Nesticus): Inferences from geographicbased sampling. Evolution 1997, 51:1929-1945.

79. Kambhampati S, Smith PT: PCR primers for the amplification of four insect mitochondrial gene fragments. Insect Mol Biol 1995, 4:233-236.

80. Giribet G, Rambla M, Carranza S, Baguna J, Riutort M, Ribera C: Phylogeny of the arachnid order Opiliones (Arthropoda) inferred from a combined approach of complete $18 \mathrm{~S}$ and partial $28 \mathrm{~S}$ ribosomal DNA sequences and morphology. Mol Phylogen Evol 1999, 11:296-307.

81. Colgan DJ, McLauchlan A, Wilson GDF, Livingston SP, Edgecombe GD, Macaranas J, Cassis G, Gray MR: Histone H3 and U2 snRNA DNA sequences and arthropod molecular evolution. Aust I Zool 1998, 46:419-437.

82. Serveis Cientificotècnics de la Universitat de Barcelona. [http://www.sct. ub.es].

83. Drummond AJ, Ashton B, Buxton S, Cheung M, Cooper A, Heled J, Kearse M, Moir R, Stones-Havas S, Thierer T, Wilson A: Geneious v5.0.3. 2010 [http://www.geneious.com].

84. MAFFT version 6. [http://mafft.cbrc.jp/alignment/server/].

85. Katoh $\mathrm{K}$, Toh $\mathrm{H}$ : Recent developments in the MAFFT multiple sequence alignment program. Brief Bioinform 2008, 9:286-298.

86. Simmons MP, Ochoterena H: Gaps as characters in sequence-based phylogenetic analyses. Syst Biol 2000, 49:369-381.

87. Pons J, Vogler AP: Size, frequency, and phylogenetic signal of multipleresidue indels in sequence alignment of introns. Cladistics 2006 22:144-156.

88. Young N, Healy J: GapCoder automates the use of indel characters in phylogenetic analysis. BMC Bioinformatics 2003, 4:6.

89. Simmons MP, Ochoterena H, Carr TG: Incorporation, relative homoplasy, and effect of gap characters in sequence-based phylogenetic analyses. Syst Biol 2001, 50:454-462.

90. Nixon KC: WinClada. Ithaca, New York: Published by the Author; v. 1.00.08 2002.

91. Maddison WP: Gene trees in species trees. Syst Biol 1997, 46:523-536.

92. Degnan JH, Rosenberg NA: Discordance of species trees with their most likely gene trees. PLOS Genet 2006, 2:762-768.

93. Kubatko LS, Degnan JH: Inconsistency of phylogenetic estimates from concatenated data under coalescence. Syst Biol 2007, 56:17-24

94. Edwards SV: Is a new and general theory of molecular systematics emerging? Evolution 2009, 63:1-19.

95. Goloboff PA, Farris JS, Nixon KC: TNT: Tree analysis using new technologies, v. 0.6 (Beta) 2003.
96. Farris JS, Albert VA, Kallersjo M, Lipscomb D, Kluge AG: Parsimony jackknifing outperforms neighbor-joining. Cladistics 1996, 12:99-124.

97. Ronquist F, Huelsenbeck JP: MrBayes 3: Bayesian phylogenetic inference under mixed models. Bioinformatics 2003, 19:1572-1574.

98. Bioportal. [http://www.bioportal.uio.no/].

99. Akaike H: Maximum likelihood identification of Gaussian autoregressive moving average models. Biometrika 1973, 60:255-265.

100. Guindon S, Gascuel O: A simple, fast, and accurate algorithm to estimate large phylogenies by maximum likelihood. Syst Biol 2003, 52:696-704.

101. Posada D: jModelTest: phylogenetic model averaging. Mol Biol Evol 2008, 25:1253-1256

102. Nylander JAA, Ronquist F, Huelsenbeck JP, Nieves-Aldrey JL: Bayesian phylogenetic analysis of combined data. Syst Biol 2004, 53:47-67.

103. Drummond AJ, Rambaut A: BEAST: Bayesian evolutionary analysis by sampling trees. BMC Evol Biol 2007, 7:214.

104. Stamatakis A: RAxML-VI-HPC: maximum likelihood-based phylogenetic analyses with thousands of taxa and mixed models. Bioinformatics 2006 22:2688-2690.

105. Miller MA, Holder MT, Vos R, Midford PE, Liebowitz T, Chan L, Hoover P, Warnow T: The CIPRES Portals. 2009 [http://www.phylo.org/sub_sections/ portal].

106. Molecular evolution, phylogenetics and epidemiology. [http://tree.bio.ed. ac.uk/software/figtree/].

107. Shimodaira $\mathrm{H}$ : An approximately unbiased test of phylogenetic tree selection. Syst Biol 2002, 51:492-508

108. Shimodaira H, Hasegawa M: CONSEL: for assessing the confidence of phylogenetic tree selection. Bioinformatics 2001, 17:1246-1247.

109. Blair Hedges S, Kumar S: Precision of molecular time estimates. Trends Genet 2004, 20:242-247.

110. Donoghue PCJ, Benton MJ: Rocks and clocks: calibrating the Tree of Life using fossils and molecules. Trends Ecol Evol 2007, 22:424-431.

111. Wunderlich J, Milki R: Description of the extinct new subfamily Microsegestriinae (Araneae: Segestriidae) in Cretaceous Lebanese amber. Beitr Araneologie 2004, 3:1867-1873.

112. Fleischer RC, McIntosh CE, Tarr CL: Evolution on a volcanic conveyor belt: using phylogeographic reconstructions and K-Ar-based ages of the Hawaiian Islands to estimate molecular evolutionary rates. Mol Ecol 1998, 7:533-545

113. Carracedo JC, Day S: Canary Islands Harpenden: Terra; 2002.

114. Ho SYM: Calibrating molecular estimates of substitution rates and divergence times in birds. J Avian Biol 2007, 38:409-414.

115. Penney D, Selden PA: Fossil spiders: the evolutionary history of a mega-diverse order Manchester: Siri Scientific Press; 2011.

116. Drummond AJ, Ho SYW, Phillips MJ, Rambaut A: Relaxed phylogenetics and dating with confidence. PLoS Biol 2006, 4:699-710.

117. Sanderson MJ: r8s: inferring absolute rates of molecular evolution and divergence times in the absence of a molecular clock. Bioinformatics 2003, 19:301-302.

118. Sanderson MJ: Estimating absolute rates of molecular evolution and divergence times: a penalized likelihood approach. Mol Biol Evol 2002, 19:101-109.

119. Yang Z: Computational molecular evolution USA: Oxford University Press; 2006.

\section{doi:10.1186/1471-2148-11-317}

Cite this article as: Bidegaray-Batista and Arnedo: Gone with the plate: the opening of the Western Mediterranean basin drove the diversification of ground-dweller spiders. BMC Evolutionary Biology 2011 11:317. 